\title{
Technical Assessment of Isothermal and Non-Isothermal Modelings of Natural Gas Pipeline Operational Conditions
}

\author{
S. Sanaye* and J. Mahmoudimehr \\ Energy Systems Improvement Laboratory (ESIL), Department of Mechanical Engineering, Iran University of Science and Technology (IUST), \\ Narmak, 16844 Tehran - Iran \\ e-mail: sepehr@iust.ac.ir - mahmoudimehr@iust.ac.ir \\ * Corresponding author
}

\begin{abstract}
Résumé - Évaluation technique de modélisations isothermes et non isothermes de conditions opérationnelles de conduites de gaz naturel - Une modélisation d'équipement au sein d'un gazoduc a été réalisée en dérivant une nouvelle forme d'ensemble d'équations de conservation pour un écoulement compressible. Une section du troisième réseau de distribution de gaz iranien (Nourabad-PatavehDorahan, N-P-D) a été ensuite étudiée selon des approches de modélisation isotherme (IT) et non isotherme (NIT) en prenant en compte les effets de la température du sol. Dans la première partie, le fonctionnement en régime stationnaire du gazoduc N-P-D, comprenant une station de compresseurs à Pataveh, a été étudié. Pour les valeurs connues de débit massique de gaz naturel et de pression de gaz d'entrée/sortie aux points Nourabad/Dorahan, les modélisations IT et NIT ont présenté respectivement des écarts maximaux en pourcentages d'environ $33,7 \%, 16,6 \%$ et $23 \%$ en ce qui concerne la tête des compresseurs, la vitesse de rotation des compresseurs et les taux de consommation de carburant. Dans la deuxième partie, le fonctionnement instable du gazoduc N-P-D, dû à l'arrêt d'un compresseur à la station de compresseurs de Pataveh (PCS: Pataveh Compressor Station), a été étudié. Les résultats ont confirmé qu'à des températures de sol faibles $\left(0\right.$ et $\left.20^{\circ} \mathrm{C}\right)$, les compresseurs restants pouvaient compenser la perte d'un compresseur. Toutefois, à des températures de sol supérieures $\left(40\right.$ et $\left.50^{\circ} \mathrm{C}\right)$, les compresseurs devaient tourner plus vite que la vitesse maximale acceptable pour parvenir à délivrer un certain débit massique sans réduction de la pression de gazoduc requise. Dans tous les cas étudiés ci-dessus, le temps de calcul de la modélisation non isotherme a été approximativement trois fois plus long que celui de la modélisation isotherme.
\end{abstract}

\footnotetext{
Abstract - Technical Assessment of Isothermal and Non-Isothermal Modelings of Natural Gas Pipeline Operational Conditions - Modeling of equipment in a gas pipeline was performed here by deriving a new form of conservation equation set for compressible flow. Then a section of the third Iranian gas transmission pipeline (Nourabad-Pataveh-Dorahan, N-P-D) was investigated by isothermal (IT) and non-isothermal (NIT) modeling approaches taking into account the effects of ground temperature. In the first part, the steady state operation of the N-P-D pipeline including a compressor station at Pataveh was studied. For the known values of natural gas mass flow rate, and inlet/outlet gas pressures at Nourabad/Dorahan points, the IT and NIT modelings showed about 33.7\%, 16.6\% and 23\% maximum difference percent points for the compressors head, compressors rotational speed and fuel consumption rates respectively. In the second part, the unsteady operation of the N-P-D pipeline due to the shutdown of a compressor at Pataveh Compressor Station (PCS) was studied. The results confirmed
} 
that at lower ground temperatures $\left(0\right.$ and $\left.20^{\circ} \mathrm{C}\right)$, the remaining compressors could compensate the loss of one compressor. However, at higher ground temperatures $\left(40\right.$ and $\left.50^{\circ} \mathrm{C}\right)$, the compressors had to run faster than the highest permissible speed to be able to deliver a certain mass flow rate without reducing the required pipeline pressure. In all above studied cases, the computing time for the non-isothermal modeling was about three times longer than that for the isothermal one.

\section{NOMENCLATURE}

A Pipe flow surface area $\left(\mathrm{m}^{2}\right)$

$C_{p} \quad$ Constant pressure heat capacity of natural gas (J/kg.K)

D Pipe diameter (m)

$f \quad$ Darcy friction factor

$g \quad$ Gravitational acceleration $\left(\mathrm{m} . \mathrm{s}^{-2}\right)$

$h \quad$ Specific enthalpy $(\mathrm{J} / \mathrm{kg})$

$H \quad$ Isentropic head $(\mathrm{J} / \mathrm{kg})$

IT Isothermal

$k \quad$ Soil thermal conductivity (W/m.K)

LHV Lower heating value of natural gas $(\mathrm{J} / \mathrm{kg})$

$\dot{m} \quad$ Mass flow rate $(\mathrm{kg} / \mathrm{s})$

$N \quad$ Buried pipe depth (m)

NIT Non-Isothermal

$p \quad$ Pressure $(\mathrm{Pa})$

$Q_{a c} \quad$ Compressor actual volumetric flow rate $\left(\mathrm{m}^{3} / \mathrm{s}\right)$

$R \quad$ Gas constant (J/kg.K)

Re Reynolds number

$S \quad$ Compressor rotational speed (rpm)

$T \quad$ Temperature (K)

$U \quad$ Overall heat transfer coefficient $\left(\mathrm{W} / \mathrm{K} \cdot \mathrm{m}^{2}\right)$

$v \quad$ Flow velocity $(\mathrm{m} / \mathrm{s})$

Z Compressibility factor

\section{Greek letters}

$\varepsilon \quad$ Pipe wall roughness (m)

$\eta \quad$ Efficiency

$\lambda \quad$ Natural gas conductivity (W/m.K)

$\theta \quad$ The pipeline slope

$\rho \quad$ Natural gas density $\left(\mathrm{kg} / \mathrm{m}^{3}\right)$

$\sigma \quad$ Isentropic exponent

\section{Subscripts}

$\begin{array}{ll}a c & \text { Actual } \\ c & \text { Critical } \\ d & \text { Discharge } \\ f & \text { Fuel } \\ i s & \text { Isentropic } \\ \text { mech } & \text { Mechanical } \\ s & \text { Suction }\end{array}$

\section{INTRODUCTION}

Mathematical modeling, as an effective and essential tool for the study of gas transmission pipeline operating conditions, permits the prediction of pipeline performance under different operating scenarios to control, design and optimize these pipelines.

From the perspective of flowing gas temperature variation, the gas pipeline can be modeled assuming either isothermal (IT) or non-isothermal (NIT). The IT model assumes that any fluctuation of the gas temperature can be quickly damped via heat transfer to the ground, causing a uniform temperature equal to the ground temperature throughout the pipeline. In most cases, this is not an accurate assumption, due to the fact that pressure drop, work of friction and heat transfer change the gas temperature as it travels through the pipeline. One very important outcome of this reality (Non-Isothermal pipeline) is that the energy equation must be solved with the momentum and continuity equations simultaneously.

There are extensive research works on modeling of the pipeline gas flow. References [1] and [2] have described the governing equations for compressible gas flows throughout the pipelines. Reference [3] simulated the natural gas flow through pipelines without neglecting any part of the momentum equation. It should be noted that in most research works the convective inertia term in the momentum equation was neglected which reduced the accuracy of the results.

Reference [4] extended the usage of electrical analogy method for transient analysis of isothermal gas flow in pipeline networks which led to the first order ordinary differential equations instead of having to solve the original partial differential equations.

Reference [2] compared the IT and NIT modeling results of the natural gas flow through pipelines. This comparison showed different pressure profiles along the gas pipeline such that the difference in pressure distribution increased with increasing the gas mass flow rate. The effect of IT and NIT type of modeling on the performance of a compressor station located in the middle of two gas pipelines was not discussed in Reference [2].

Reference [5] proposed a general flow equation for estimating the performance of gas pipeline and showed that taking into account the effects of ambient conditions was necessary to obtain accurate results.

References [6] and [7] proposed new forms of governing equations for compressible gas flow in which mass flow rate was substituted for flow velocity. 
For isothermal and steady state conditions, a variety of general forms of flow equations have been developed and proposed by researchers based on various friction equations for estimating the pipeline pressure drop [8-10].

Pressure drop occurs due to both friction and heat transfer to the pipeline surroundings. This pressure drop is compensated by appropriate number of compressor stations existing in a pipeline. Reference [11] studied the application of dynamic simulation for the design and control of compressors. Dynamic behavior of compressor stations was also modeled by $[12,13]$. These modeling approaches involved deriving a set of nonlinear partial differential equations describing the pipe flow as well as deriving a set of nonlinear algebraic equations describing the flow passing through compressors and valves. The compressibility and friction factors were considered constant in these research studies as simplified assumptions.

It is worth mentioning that the number of research works on NIT modeling is less than those for the IT modeling. This could be the result of simpler form of conservative equations for IT modeling as well as its shorter computing time.

Contributions of this paper into the subject are as follows:

- proposing a new form of governing equations for the nonisothermal, unsteady and compressible gas flow through the pipeline as a function of mass flow rate, pressure and temperature;

- modeling the gas turbine in compressor station to consider the effects of part load, ambient temperature and shaft speed on the gas turbine efficiency;

- evaluating the deviations of predicted isothermal modeling results from the non-isothermal modeling ones (as an operating condition which is closer to the real operating conditions of gas flow in pipelines) for different ground temperatures;

- evaluating the effect of ground temperature on the gas pipeline operating condition under steady state and unsteady conditions;

- comparison of running times required for two isothermal and non-isothermal approaches in the gas pipeline modeling.

\section{GOVERNING EQUATIONS}

A gas pipeline is composed of pipeline, junctions and compressor station with gas turbines and compressors as the main components. In this paper to simulate the flow in a pipeline, a set of nonlinear equations were derived and solved using the Newton-Raphson method. These equations are introduced in the next section.

\subsection{Pipeline}

Equations (1-3) show the governing equations related to gas flows in pipelines $[2,6,14]$ :

$$
\text { Continuity: } \frac{\partial \rho}{\partial t}+\frac{\partial(\rho v)}{\partial x}=0
$$

Momentum : $\quad \rho \frac{\partial v}{\partial t}+\rho v \frac{\partial v}{\partial x}+\frac{\partial p}{\partial x}=-f \frac{\rho v|v|}{8 A} \pi D-\rho g \sin \theta$ (2)

$$
\text { Energy: } \quad \rho \frac{d h}{d t}-\frac{d p}{d t}=\frac{\Omega}{A}+f \frac{\rho v^{2}|v|}{8 A} \pi D+\frac{\partial}{\partial x}\left(\lambda \frac{\partial T}{\partial x}\right)
$$

In which $\Omega$ is defined as follows:

$$
\Omega=\frac{4 U A\left(T-T_{\text {ground }}\right)}{D}
$$

Generally, in gas transmission pipelines, the axial conduction heat transfer in gas flow is negligible in comparison with the axial flow enthalpy; therefore the last term in RHS of the energy equation may be ignored [15]. In this regard, Reference [2] showed that, while the magnitude of other terms in energy equation were in order of $10^{2}$ to $10^{7}$ (using scale analysis), the last term in RHS had just the order of $10^{-5}$. The overall heat transfer coefficient is the combined effects of convection heat transfer between gas and pipe wall and conduction heat transfer between pipe wall and soil. Assuming the soil conductive resistance to be the dominant heat transfer resistance [16], the overall heat transfer coefficient can be estimated using the following Equation [17]:

$$
U=\frac{2 k}{D \operatorname{Ln}\left[\frac{2 N}{D}+\sqrt{4\left(\frac{N}{D}\right)^{2}-1}\right]}
$$

where $D$ and $N$ are the pipe diameter and buried pipe depth respectively.

Therefore with six unknowns in Equations (1-3) ( $\rho, v, p, f$, $h, T)$, three supplementary equations were required. The first supplementary equation was obtained by expressing the friction factor as a function of the Reynolds number and the pipe roughness. Various correlations have been proposed in Reference [16] for calculating the natural gas flow friction factor. Using a reliable explicit friction factor equation could reduce the computing time.

Haaland Equation [18] (Eq. 6) was used in this paper for estimating the friction factor. The numerical results of this equation differ from Colebrook-White equation (which is very accurate and in implicit form) for about $0.5 \%$ in average [16]:

$$
f=4\left(-3.6 \log \left(\left(\frac{\varepsilon}{3.7 D}\right)^{1.11}+\frac{6.9}{R e}\right)\right)^{-2}
$$


Enthalpy of real gasses as a function of pressure and temperature [19] $(E q .7)$ provides the second supplementary equation:

$$
d h=c p d T+\left(1+\frac{T}{\rho}\left(\frac{\partial \rho}{\partial T}\right)_{p}\right) \frac{d p}{\rho}
$$

Finally, the gas state equation (Eq. 8) was considered as the third supplementary equation:

$$
\rho=\frac{p}{Z(p, T) \cdot R \cdot T}
$$

For which, Equation (9) was used for compressibility factor as a function of the reduced pressure (the ratio of actual pressure to the gas critical pressure, $p / p_{c}$ ), and the reduced temperature (the ratio of actual temperature to the gas critical temperature, $T / T_{c}$ ) [20-22]:

$$
Z=1+0.257 \frac{p}{p_{c}}-0.533\left(\frac{p}{p_{c}}\right)\left(\frac{T_{C}}{T}\right)
$$

Although there are more accurate equations of state, EOS, (e.g. AGA, SRK, PR and BWRS [23], and GERG [24]) or correlations for compressibility factors (e.g. relations presented by Hall and Yarborough [25], Dranchuck et al. [26], Dranchuck and Aboukasem [27]) than Equation (9), the simple and explicit form of compressibility factor of Equation (9) gives the advantage of saving computational time especially in the optimization applications where natural gas pipeline network have to be simulated repeatedly. Furthermore, it has been recently shown that the form of the EOS for natural gas used in the pipeline model has relatively small influence on pressure-temperature values in the solution and only really matters in leak-detection systems, or when pipeline line-pack (inventory) rather than pressure is controlled by the compressors [28].

In gas pipeline applications, it is preferable to work with the gas mass flow rate instead of the gas velocity with the following conversion equation:

$$
v=\frac{\dot{m}}{\rho A}=\frac{\dot{m} Z R T}{p A}
$$

Based on the gas mass flow rate, the following new form of conservation equations were derived as shown in Appendix 1 and are proposed here as: see Equations (11-13).

The derivation of the above equations and the equations proposed in [6] and [7] started with the same governing equations and the same idea of using gas mass flow rate instead of gas velocity. However, the above proposed forms of conservation equations in this paper as well as the way of their derivation were different from those proposed by [6] and [7].

The set of partial differential equations (Eq. 11-13) were solved using fully implicit finite difference method with the following discretized forms:

$$
\begin{gathered}
\phi=\frac{\phi_{i+1}^{t+1}+\phi_{i}^{t+1}}{2} \\
\frac{\partial \phi}{\partial x}=\frac{\phi_{i+1}^{t+1}-\phi_{i}^{t+1}}{\Delta x} \\
\frac{\partial \phi}{\partial t}=\frac{\phi_{i+1}^{t+1}+\phi_{i}^{t+1}-\phi_{i+1}^{t}-\phi_{i+1}^{t}}{2 \Delta t}
\end{gathered}
$$

where $\phi$ denotes for each of the $\dot{m}, p, T$ in Equations (11-13).

\subsection{Compressor}

A schematic diagram of a compressor driven by a gas turbine engine is shown in Figure 1. Compressors are modeled with the quasi-steady assumption, therefore the compressor characteristics as well as its suction and discharge states were assumed to be constant at each time step.

Equations (17-23) show the governing equations of gas flow passing through a typical compressor.

The ratio of compressor isentropic head to the square of rotational speed:

$$
\frac{H}{S^{2}}=b_{1}+b_{2}\left(\frac{Q_{a c}}{S}\right)+b_{3}\left(\frac{Q_{a c}}{S}\right)^{2}
$$

Compressor isentropic efficiency:

$$
\eta_{i s}=b_{4}+b_{5}\left(\frac{Q_{a c}}{S}\right)+b_{6}\left(\frac{Q_{a c}}{S}\right)^{2}
$$

$$
\begin{gathered}
\text { Continuity: }\left(\frac{z R T}{A}\right) \frac{\partial \dot{m}}{\partial x}+\left(1-\frac{p}{z} \frac{\partial z}{\partial p}\right) \frac{\partial p}{\partial t}+\left(-\frac{p}{T}-\frac{p}{z} \frac{\partial z}{\partial T}\right) \frac{\partial T}{\partial t}=0 \\
\text { Momentum: }\left(-\frac{\dot{m}^{2} z}{p}+\dot{m}^{2} \frac{\partial z}{\partial p}+\frac{p A^{2}}{R T}\right) \frac{\partial p}{\partial x}+\left(-\frac{A \dot{m}}{R T}+\frac{p A \dot{m}}{z R T} \frac{\partial z}{\partial p}\right) \frac{\partial p}{\partial t}+z \dot{m} \frac{\partial \dot{m}}{\partial x}+\frac{p A}{R T} \frac{\partial \dot{m}}{\partial t}+\left(\frac{\dot{m}^{2} z}{T}+\dot{m}^{2} \frac{\partial z}{\partial T}\right) \frac{\partial T}{\partial x}+ \\
\left(\frac{p A \dot{m}}{R T^{2}}+\frac{p A \dot{m}}{z R T} \frac{\partial z}{\partial T}\right) \frac{\partial T}{\partial t}+\frac{f \dot{m}|\dot{m}| \pi D z}{8 A}+g \sin \theta \frac{p^{2} A^{2}}{z(R T)^{2}}=0 \\
\text { Energy: }(\dot{m} c p) \frac{\partial T}{\partial x}+\left(\frac{A p c p}{z R T}\right) \frac{\partial T}{\partial t}+\left(-\frac{\dot{m} z R T}{p}-\frac{\dot{m} R T^{2}}{p} \frac{\partial z}{\partial T}\right) \frac{\partial p}{\partial x}+\left(-A-\frac{A T}{z} \frac{\partial z}{\partial T}\right) \frac{\partial p}{\partial t}-\Omega-\frac{f \dot{m}^{2}|\dot{m}| \pi D}{8 A^{3}}\left(\frac{z R T}{p}\right)^{2}=0
\end{gathered}
$$




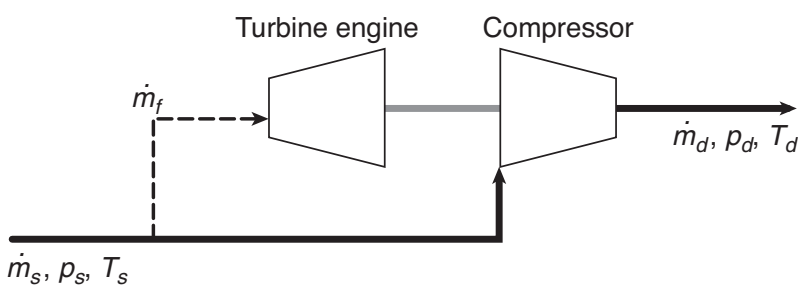

Figure 1

The schematic view of a turbo-compressor unit.

Equations (17) and (18) are empirical equations proposed in References $[29,30]$ for compressor operating points, in which $b_{1}$ to $b_{6}$ are constants that could be obtained from a specific compressor map in a pipeline.

Compressor isentropic head in terms of compressor pressure ratio:

$$
H=\frac{Z_{s} R T_{s}}{\sigma}\left[\left(\frac{p_{d}}{p_{s}}\right)^{\sigma}-1\right]
$$

The compressor discharge temperature after gas compression:

$$
T_{d}=T_{s}+\frac{T_{s}}{\eta_{i s}}\left[\left(\frac{p_{d}}{p_{s}}\right)^{\sigma}-1\right]
$$

It is noteworthy that the pipeline modeling presented in this paper (Sect. 1.1) takes into account the real-gas effects, while Equations (19) and (20) are based on ideal-gas model. This is a commonly adopted simplification in pipeline flow simulations as indicated in Reference [31].

The compressor power consumption in terms of compressor mechanical efficiency $\left(\eta_{\text {mech }}\right)$ :

$$
\text { Power }_{\text {shaft }}=\frac{H . \dot{m}_{d}}{\eta_{\text {is }} \cdot \eta_{\text {mech }}}
$$

The required fuel mass flow rate in gas turbines for running the compressors:

$$
\dot{m}_{f}=\frac{\text { Power }_{\text {shaft }}}{L H V \cdot \eta_{\text {turbine }}}
$$

Equation (23) indicates the mass balance among the mass flow rate of natural gas entering the turbo-compressor unit $\left(\dot{m}_{s}\right)$, the gas turbine fuel consumption rate $\left(\dot{m}_{f}\right)$ and the mass flow rate of natural gas passing through the compressor $\left(\dot{m}_{d}\right)$ as indicated in Figure 1:

$$
\dot{m}_{f}+\dot{m}_{d}=\dot{m}_{s}
$$

In the above equations, subscriptions $s$ and $d$ indicate compressor suction and discharge points.
The actual volumetric flow rate passing through a compressor as a function of mass flow rate, pressure and temperature, was also obtained from:

$$
Q_{a c}=\frac{\dot{m}_{d} Z_{s} R T_{s}}{p_{s}}
$$

\subsection{Gas Turbine (Turbine Engine)}

Generally, two-shaft gas turbines are used in gas pipeline applications because of their operational flexibility [32]. A schematic diagram of a two-shaft gas turbine is shown in Figure 2. A gas turbine (including air compressor, combustion chamber, low and high pressure turbines) provides power to run the air compressor by the high pressure turbine and to run the pipeline compressor by the low pressure turbine (sometimes called power turbine).

For any shaft speed and power required by the pipeline compressor, the driver (turbine engine) operational condition should be adjusted. Generally, the technical information regarding the turbine engine includes the maximum output shaft speed $\left(S_{\max }\right)$, and its base load maximum power output and efficiency at ISO conditions (point labeled with A in Fig. 3). Ambient temperature and pressure values of $15^{\circ} \mathrm{C}$ and $101.325 \mathrm{kPa}$ were considered for ISO conditions. In most cases though, the turbine does not operate at ISO conditions due to the elevation or temperature of the site in which the engine is installed as well as running at the partial load and/or out of design speed. therefore, some corrections are required for computing the turbine engine overall performance as follows:

\subsubsection{Correction for the ambient temperature}

The ambient temperature variation changes the values of output shaft speed, power and efficiency [33, 34] at the design point. For example, movement of point A to B in Figure 3 shows the effect of a typical change in atmospheric temperature from $T_{\text {iso }}$ to $T_{\text {ambient } \neq i s o}$.

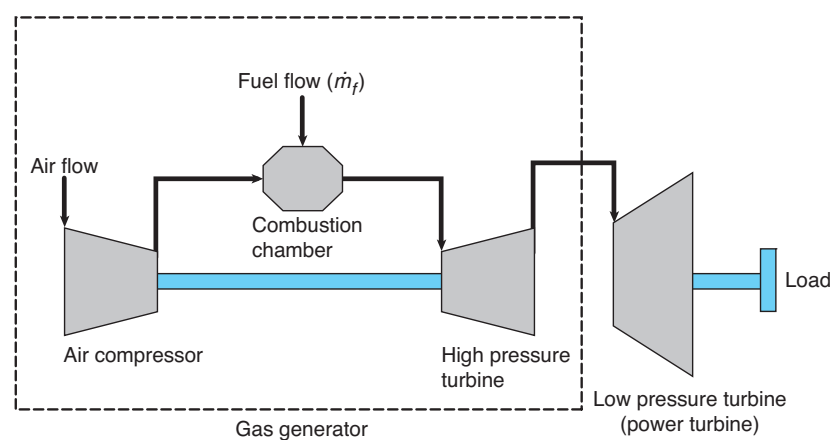

Figure 2

The schematic view of a two-shaft turbine engine. 


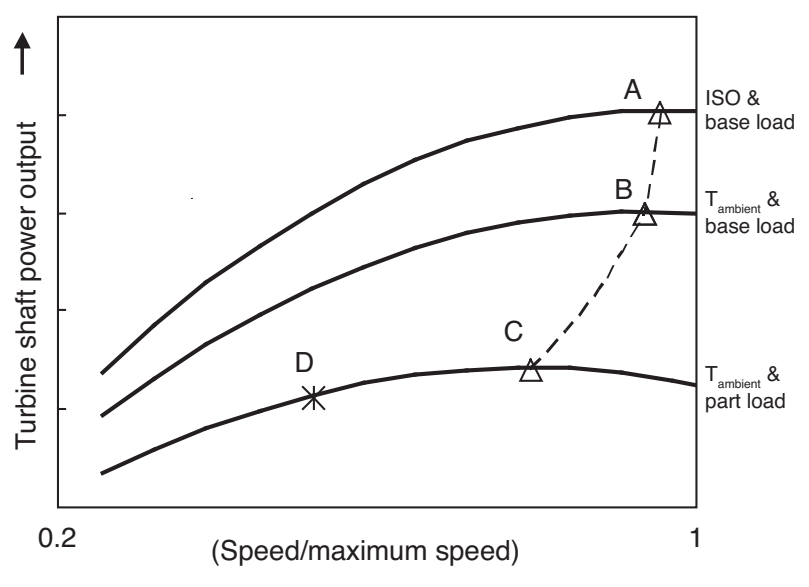

Figure 3

Schematic diagram of a typical gas turbine engine performance map.

Therefore, some equations are required to estimate these effects. These equations can be extracted using the map or data available for a specific turbine which have the following forms:

$$
\begin{gathered}
\frac{\text { Power }_{A}}{\text { Power }_{B}}=f_{1}\left(\frac{T_{\text {ambient }}(K)}{T_{\text {iso }}(K)}\right) \\
\frac{\eta_{A}}{\eta_{B}}=f_{2}\left(\frac{T_{\text {ambient }}(K)}{T_{\text {iso }}(K)}\right) \\
\frac{S_{B}}{S_{\max }}=f_{3}\left(\frac{T_{\text {ambient }}(K)}{T_{\text {iso }}(K)}\right)
\end{gathered}
$$

\subsubsection{Correction for the part load operation}

The turbine part load operation decreases the optimal values of output shaft speed, power and efficiency [33, 35]. For example, movement of point $\mathrm{B}$ to $\mathrm{C}$ in Figure 3 shows the effect of a typical part load operation. Equations which consider these effects are:

$$
\begin{gathered}
\frac{\eta_{C}}{\eta_{B}}=f_{4}\left(\frac{\text { Power }_{C}}{\text { Power }_{B}}\right) \\
\frac{S_{C}}{S_{B}}=f_{5}\left(\frac{\text { Power }_{C}}{\text { Power }_{B}}\right)
\end{gathered}
$$

\subsubsection{Correction for the operation out of design rotational speed}

For any operating condition of a gas generator (part of the gas turbine confined in a dashed box in Fig. 2), there is a rotational speed at which the output shaft power and efficiency are the highest. If the power turbine deviates from this speed, the power and efficiency decrease with the same propor-

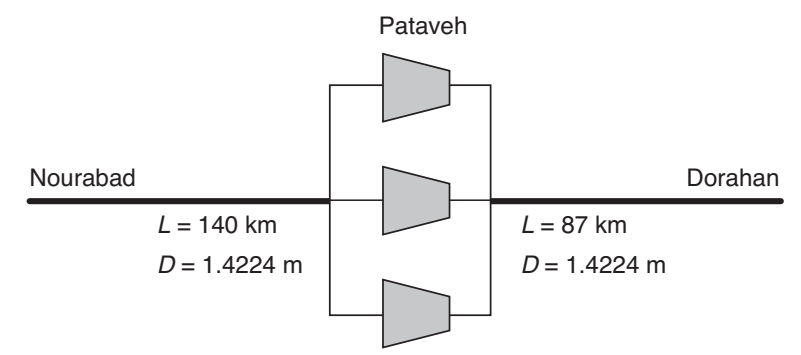

Figures 4

A section of the third Iranian gas transmission pipeline with a station including three running compressors during steady state operation and with one compressor shut down during unsteady analysis.

tions [33]. For example, movement of point $\mathrm{C}$ to $\mathrm{D}$ in Figure 3 shows the effect of a typical change in turbine shaft rotational speed from its optimal value.

Equations (30) and (31) were proposed by [33] and [36] to take this effect into consideration:

$$
\begin{aligned}
\frac{\text { Power }_{\text {shaft }}}{\text { Power }_{C}} & =2\left(\frac{S}{S_{C}}\right)-\left(\frac{S}{S_{C}}\right)^{2} \\
\frac{\eta_{\text {driver }}}{\eta_{C}} & =\frac{\text { Power }_{\text {shaft }}}{\text { Power }_{C}}
\end{aligned}
$$

In the above equations, Power $_{\text {shaft }}$ and $S$ are the required turbine engine output shaft power and speed (point $\mathrm{D}$ ) by the pipeline compressor.

\section{CASE STUDY}

This study was conducted for a section of the third Iranian gas transmission pipeline (Nourabad-Pataveh-Dorahan (N-PD)), shown schematically in Figure 4, which is responsible for gas transmission from Nourabad to Dorahan including a compressor station (equipped with three compressors) located at Pataveh.

Pipeline inlet gas pressure, inlet temperature and volumetric flow rate were 7.24 MPa, $40^{\circ} \mathrm{C}$, and $80 \mathrm{MMSCMD}$ (million standard cubic meters per day) respectively. Also the required pipeline outlet pressure (at Dorahan) was 5.86 MPa.

Table 1 shows the gas properties, soil conductivity, pipe roughness and the buried pipe depth for the above gas pipeline.

The maximum rotating speed of turbine shaft $\left(S_{\max }\right)$, and the base load maximum power and efficiency at ISO conditions are $7700 \mathrm{rpm}, 25.4 \mathrm{MW}$, and 35.1\%, respectively.

Constant coefficients of four second order polynomial equations $\left(a x^{2}+b x+c\right)$ which were obtained (by curve fitting) for the functions $f_{1}$ to $f_{3}$ and $f_{5}$ in Equations (25-27) and 
TABLE 1

Gas properties, soil conductivity, pipe roughness and buried pipe depth for N-P-D pipeline

\begin{tabular}{c|c|c|c|c|c}
\hline $\begin{array}{c}\text { Soil } \\
\text { conductivity } \\
(\mathrm{W} / \mathrm{m} . \mathrm{K})\end{array}$ & $\begin{array}{c}\text { Pipe } \\
\text { roughness } \\
(\mu \mathrm{m})\end{array}$ & $\begin{array}{c}\text { Burying } \\
\text { depth } \\
(\mathrm{m})\end{array}$ & $\begin{array}{c}\text { Gas } \\
\text { viscosity } \\
(\text { Pa.s })\end{array}$ & $\begin{array}{c}\mathrm{Cp} \\
(\mathrm{kJ} / \mathrm{kg} \cdot \mathrm{K})\end{array}$ & $\begin{array}{c}\text { Gas } \\
\text { constant } \\
(\mathrm{J} / \mathrm{kg} . \mathrm{K})\end{array}$ \\
\hline 2 & 35 & 1.7 & $1.2 \times 10^{-5}$ & 2.171 & 467.8 \\
\hline
\end{tabular}

TABLE 2

Constant coefficients of the functions $f_{1}$ to $f_{3}$ and $f_{5}$ in Equations (25-27) and (29)

\begin{tabular}{c|c|c|c}
\hline Function & $a$ & $b$ & $c$ \\
\hline$f_{1}$ & -4.3115 & 6.6618 & -1.3618 \\
\hline$f_{2}$ & -2.4918 & 4.4951 & -1.0074 \\
\hline$f_{3}$ & -0.4081 & 0.6405 & 0.7222 \\
\hline$f_{5}$ & -0.397 & 1.0165 & 0.3777 \\
\hline
\end{tabular}

(29) are shown in Table 2. Also, a logarithmic function was obtained for $f_{4}$ in the form of $f_{4}=0.2457 \operatorname{Ln}(x)+1$.

Figure 5 compares the functions used in this paper taking into account the effects of ambient temperature and part load operation on the gas turbine performance with those proposed by Zhang and Cai [37]. This figure shows maximum and average difference values of about $10.3 \%$ and $3.9 \%$ for $f_{1}$, $3.6 \%$ and $1.23 \%$ for $f_{2}$, and $3 \%$ and $0.8 \%$ for $f_{4}$ respectively.

One kilometer was considered for pipeline discretisation or step size for both IT and NIT modeling approaches. When the distance step size was decreased from $1 \mathrm{~km}$ to $0.5 \mathrm{~km}$, the maximum change in temperature and pressure values along the pipeline were about $3 \times 10^{-4} \%$ and $7 \times 10^{-6} \%$ respectively. Furthermore, one minute was considered as the time step size for unsteady operation modeling.

\section{DISCUSSION AND RESULTS}

\subsection{Modeling Verification}

To verify the modeling procedure and results proposed in this paper, the modeling results were compared with those reported in Reference [38] for the same input values. The case study in Reference [38] is shown schematically in Figure 6. It included a pipeline with a compressor station (equipped with two compressors) located at the middle. This pipeline transmitted 350 MMSCFD gas volume flow rate with inlet and outlet gas pressures of 104.6 and 56.8 baras (absolute pressure in bars) respectively. Pipe diameter and roughness were also $0.4953 \mathrm{~m}$ and $18 \mu \mathrm{m}$ respectively.
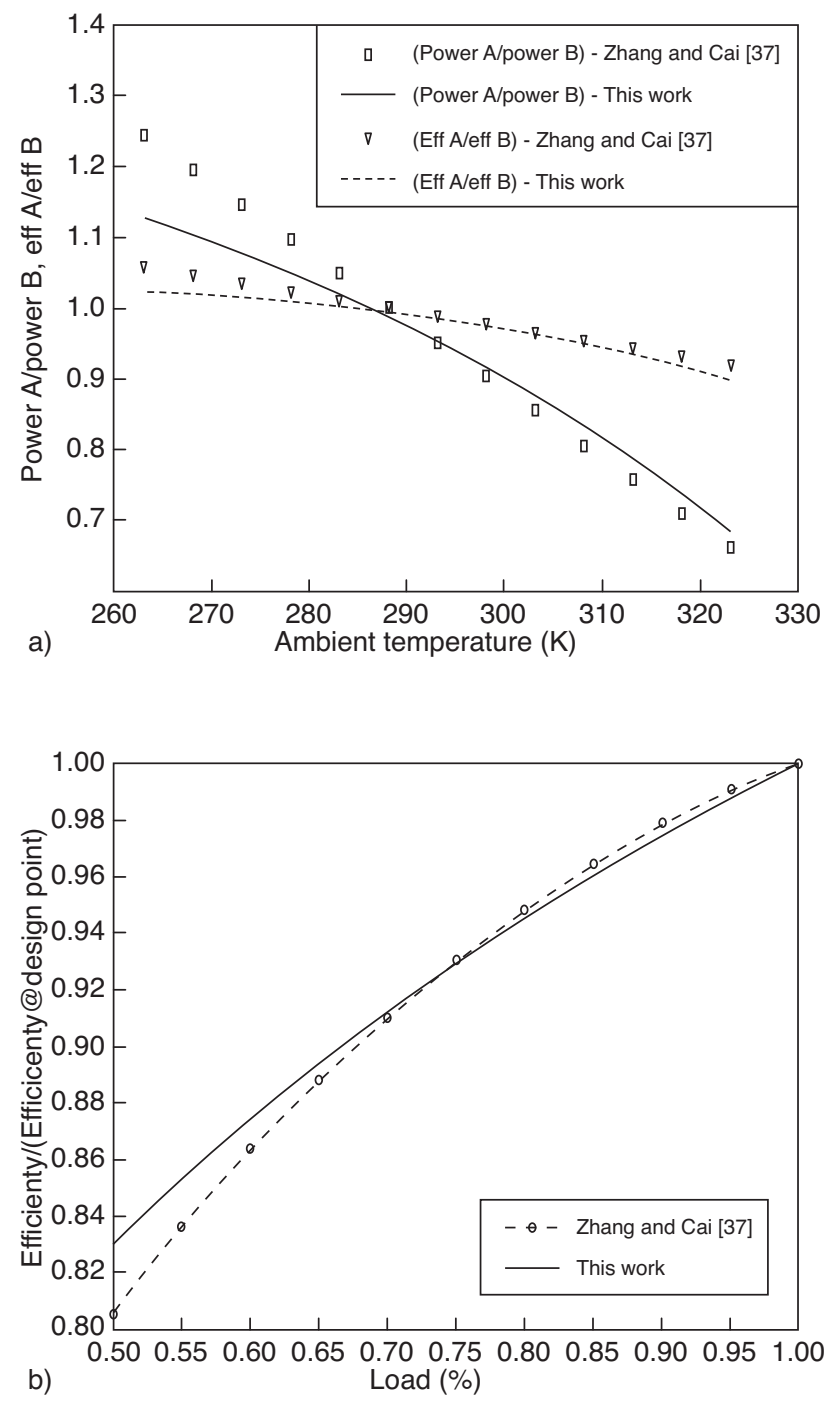

Figure 5

Comparison of $f_{1}, f_{2}, f_{4}$ values with the corresponding ones proposed by Zhang and Cai [37]. a) The effect of ambient temperature on power output and efficiency $\left(f_{1}, f_{2}\right)$; b) the effect of part load operation on gas turbine efficiency $\left(f_{4}\right)$.

During steady state operation with the specified inlet and outlet gas pressures (104.6 and 56.8 baras respectively) and compressor rotating speeds (13 $116 \mathrm{rpm}$ ), the natural gas mass flow rate passing through the pipeline computed by our modeling procedure had only 0.9 percentage point difference with the results reported in [38].

After an hour of steady state operation, one compressor was shut down and forced the other running compressors to provide the maximum power of $3580 \mathrm{~kW}$. During the unsteady operation, the pipeline inlet pressure and outlet mass flow rate remained unchanged. Reference [38] modeled the problem with the isothermal assumption with the flowing 


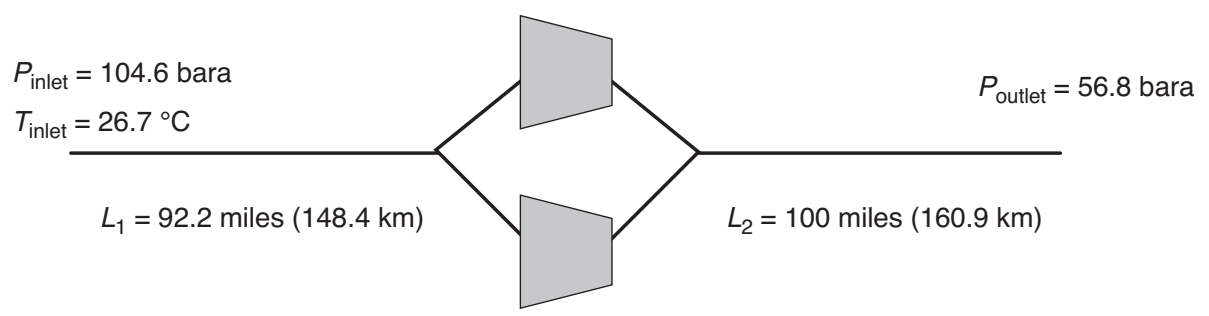

Figure 6

The schematic view of the case study reported in [38].
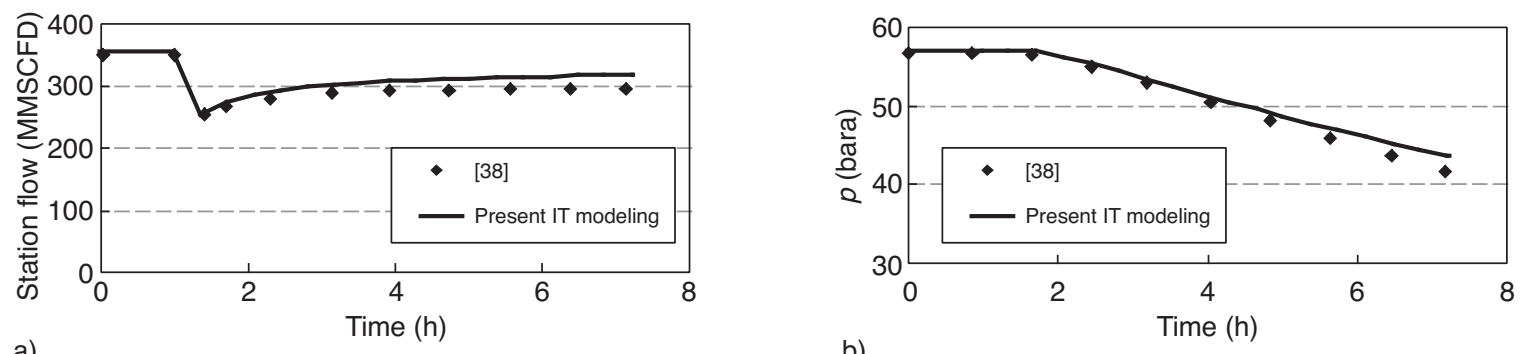

Figure 7

The comparison between the results reported in Reference [30] and the results obtained from the presented numerical modeling:

a) time variation of mass flow rate in compressor station, b) time variation of the pipeline outlet pressure.

gas average temperature value of $26.7^{\circ} \mathrm{C}$. Compressor constants of Equations (17) and (18) were obtained from the given compressor map in Reference [38] and are shown in Table 3.

\section{TABLE 3}

Compressor constant values based on information provided in Reference [38]

\begin{tabular}{c|c|c|c|c|c}
\hline$b_{1}$ & $b_{2}$ & $b_{3}$ & $b_{4}$ & $b_{5}$ & $b_{6}$ \\
\hline $3.6476 \times 10^{-4}$ & 4.8921 & $-6.4415 \times 10^{4}$ & 21.7834 & $1.9451 \times 10^{6}$ & $-1.5115 \times 10^{10}$ \\
\hline
\end{tabular}

The comparison between the results of the presented modeling approach and the results of Reference [38] are shown in Figure 7. The comparison yields maximum and average difference values of about $4 \%$ and $1.2 \%$ respectively, for the time variation of pipeline outlet pressure, and $4.7 \%$ and $2.5 \%$ for the time variation of station mass flow rate which shows a good agreement.

\subsection{N-P-D Pipeline (Steady State Operation)}

In this section, the differences caused by the IT and NIT approaches in gas pipeline modeling were estimated and the effects of ground temperature on the gas pipeline performance was investigated for the steady state operation of N-P-D pipeline.

\subsubsection{The comparison of gas temperature variation computed by IT and NIT modeling approaches}

The gas temperature variations along the pipeline obtained from the IT and NIT modeling approaches are shown in Figure 8 for various ground temperatures $\left(0,20,40,50^{\circ} \mathrm{C}\right)$.

Two factors which affected the natural gas temperature variation in a pipeline were heat transfer between the gas (pipe walls) and soil, as well as Joule-Thomson effect (temperature decrease with pressure drop in natural gas).

For those cases in which the natural gas temperature was higher than the ground temperature, both the above mentioned factors caused the natural gas to cool down along the pipeline. These cases included both inlet and outlet Pataveh Compressor Station (PCS) pipelines for the ground temperatures of $0,20^{\circ} \mathrm{C}$ (with the natural gas temperature variations shown in Fig. 8a, b) as well as outlet PCS pipeline for the ground temperatures of $40,50^{\circ} \mathrm{C}$ (with the natural gas temperature variations shown in Fig. $8 c, d$ ).

For those cases in which the natural gas temperature was lower than the ground temperature, the variation of the natural gas temperature along the pipeline was the resultant of two mentioned opposite effects (heat transfer from the soil to the natural gas, and cooling down as a result of Joule-Thomson effect). The above mentioned cases included inlet PCS pipeline for the ground temperatures of $40,50^{\circ} \mathrm{C}$ (Fig. $\left.8 c, d\right)$. 

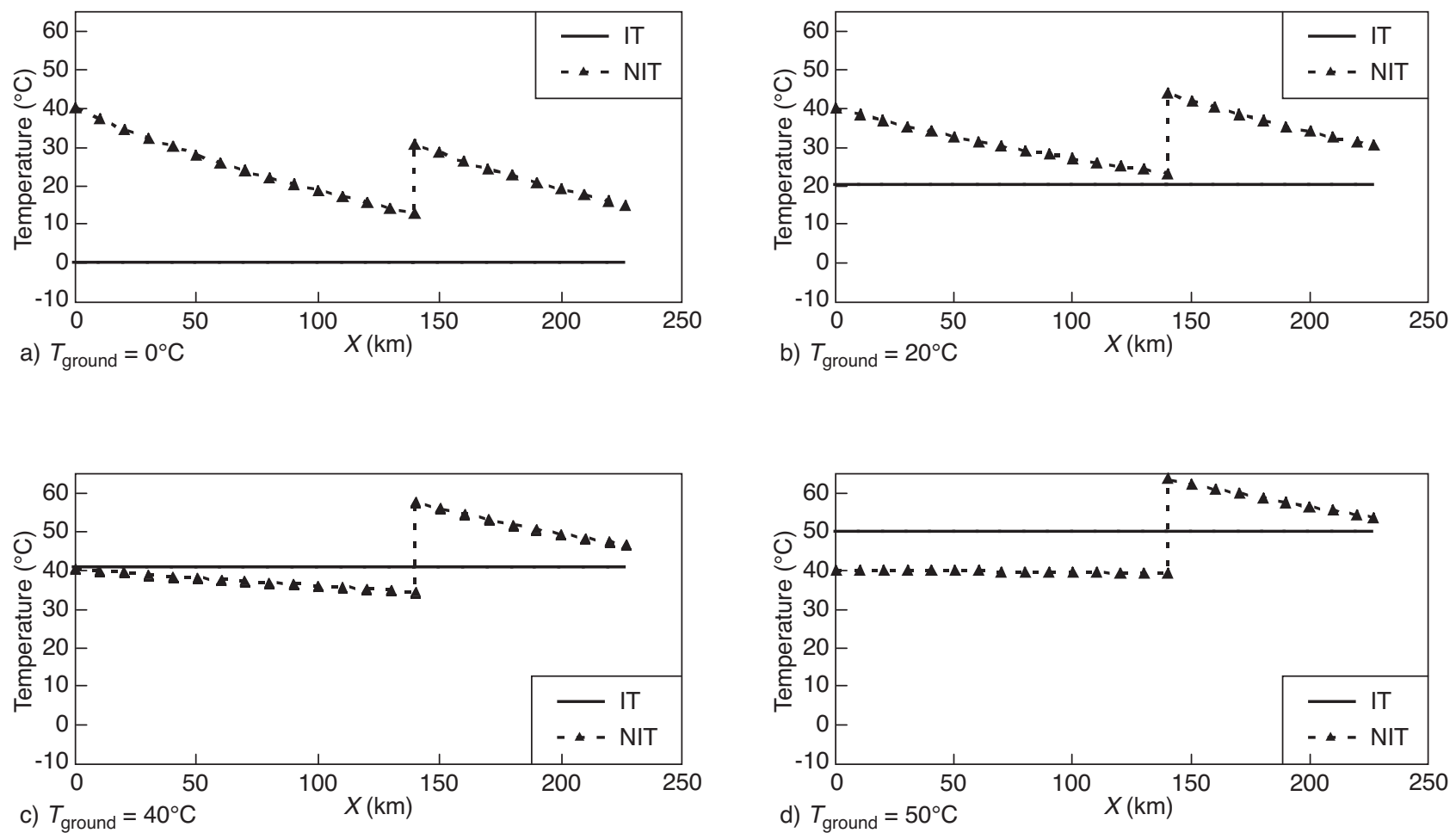

Figure 8

Comparison of the gas flow temperatures in Nourabad-Dorahan pipeline obtained from IT and NIT modeling approaches for various ground temperatures.

As is shown in Figure 8d the gas temperature along the inlet PCS pipeline varied very smoothly.

An important point is that as Figure 8a-d show, a jump in temperature due to the gas compression at PCS was ignored by the IT modeling approach.

\subsubsection{The comparison of gas pressure variation computed by IT and NIT modeling approaches}

The gas pressure variation along the pipeline obtained from the IT and NIT modeling approaches are shown in Figure 9 for various ground temperatures $\left(0,20,40,50^{\circ} \mathrm{C}\right)$.

In general, with gas temperature drop (increase of gas density) for a fixed mass flow rate $(\dot{m}=\rho A v)$, the volumetric flow rate $(A v)$ and frictional resistance (absolute value of the first term in RHS of $E q .2$ ) decrease and therefore, a lower pressure drop occurs in the pipeline. Therefore, for a fixed mass flow rate, a higher flowing gas temperature caused a higher pressure loss in the pipeline.

The comparison of Figure 9a, b with Figure 8a, b shows that NIT modeling approach predicted the higher pressure drop in both inlet and outlet PCS pipelines than that for IT modeling. This is due to a higher gas flow temperature along the N-P-D pipeline predicted by NIT modeling approach.
This resulted in a need for a higher pressure increase at the compressor station for this type of pipeline modeling.

Figure 9c, d shows that the NIT modeling approach predicted a lower pressure drop for inlet PCS pipeline and a higher pressure drop for outlet PCS pipeline in comparison with the IT modeling. This observation is consistent with the temperature variations predicted by the two modeling approaches shown in Figure 8c, d in which the NIT modeling predicted the lower gas flow temperature along the inlet PCS pipeline and the higher gas flow temperature at the outlet PCS pipeline in comparison with the IT modeling.

\subsubsection{The comparison of compressor operational parameters and fuel consumption rates at the PCS computed by IT and NIT modeling approaches}

Table 4 compares the compressor head, compressor rotational speed and fuel consumption rate obtained from the IT and NIT modeling approaches for various ground temperatures $\left(0,20,40,50^{\circ} \mathrm{C}\right)$.

This table shows the higher values of the above mentioned parameters predicted by NIT modeling approach in comparison with the IT modeling approach with the difference percent points of $33.7 \%, 16.6 \%$ and $23 \%$ respectively for $0^{\circ} \mathrm{C}$ 

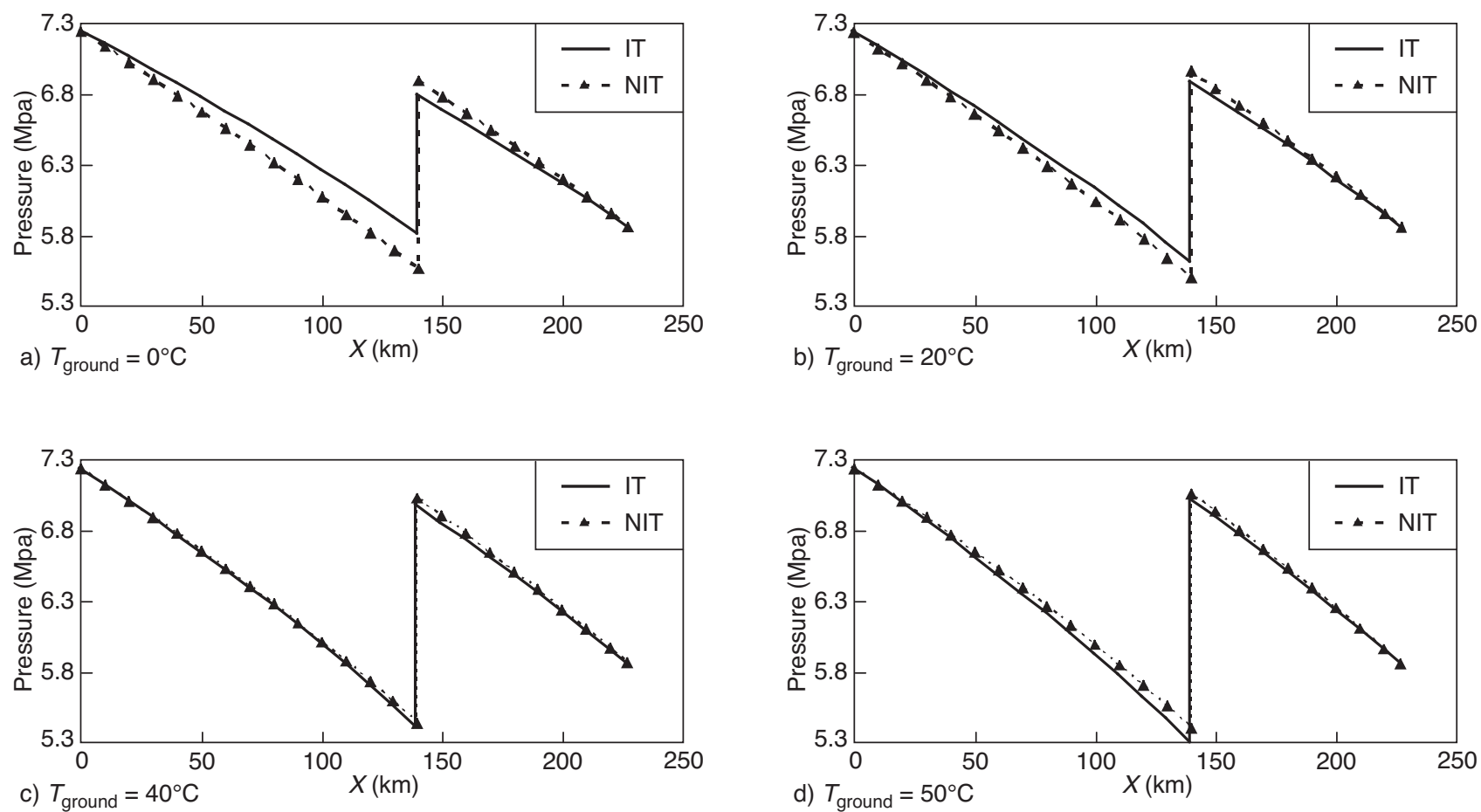

Figure 9

Comparison of the gas flow pressures in Nourabad-Dorahan pipeline obtained from IT and NIT modeling approaches for various ground temperatures.

TABLE 4

Comparison of compressor heads, speeds and fuel consumption rates obtained from IT and NIT modeling in N-P-D pipeline for various ground temperatures

\begin{tabular}{|c|c|c|c|c|c|c|c|c|c|}
\hline \multirow[b]{2}{*}{$\begin{array}{l}T_{\text {ground }} \\
\left({ }^{\circ} \mathrm{C}\right)\end{array}$} & \multicolumn{3}{|c|}{ Head $(\mathrm{kJ} / \mathrm{kg})$} & \multicolumn{3}{|c|}{ Compressor speed (rpm) } & \multicolumn{3}{|c|}{ Rate of fuel consumption $(\mathrm{kg} / \mathrm{s})$} \\
\hline & $\begin{array}{c}\text { Isothermal } \\
\text { (IT) }\end{array}$ & $\begin{array}{c}\text { Non-isothermal } \\
(\mathrm{NIT})\end{array}$ & Difference $\%$ & $\begin{array}{c}\text { Isothermal } \\
\text { (IT) }\end{array}$ & $\begin{array}{c}\text { Non-isothermal } \\
\text { (NIT) }\end{array}$ & Difference $\%$ & $\begin{array}{c}\text { Isothermal } \\
\text { (IT) }\end{array}$ & $\begin{array}{c}\text { Non-isothermal } \\
(\mathrm{NIT})\end{array}$ & Difference $\%$ \\
\hline 0 & 17.208 & 25.936 & 33.7 & 4929.4 & 5910.5 & 16.6 & 0.4934 & 0.6404 & 23 \\
\hline 20 & 25.508 & 30.159 & 15.4 & 5914.5 & 6358 & 7 & 0.6193 & 0.6928 & 10.6 \\
\hline 40 & 35.443 & 34.7 & -2.1 & 6919.5 & 6807.5 & -1.6 & 0.7611 & 0.7473 & -1.8 \\
\hline 50 & 41.066 & 37.091 & -10.7 & 7431.7 & 7033.1 & -5.7 & 0.8387 & 0.7753 & -8.2 \\
\hline
\end{tabular}

ground temperature case, and $15.4 \%, 7 \%$ and $10.6 \%$ respectively for $20^{\circ} \mathrm{C}$ ground temperature case. However, Table 4 shows the lower values of the above mentioned parameters predicted by NIT modeling approach in comparison with the IT modeling approach with the difference percent points of $2.1 \%, 1.6 \%$ and $1.8 \%$ respectively for $40^{\circ} \mathrm{C}$ ground temperature case, and $10.7 \%, 5.7 \%$ and $8.2 \%$ respectively for $50^{\circ} \mathrm{C}$ ground temperature case. These observations were consistent with the pressure jumps at PCS predicted by the two modeling approaches shown in Figure 9. For example, Figure 9a shows that for the ground temperature of $0^{\circ} \mathrm{C}$, NIT modeling approach predicted a higher pressure jump at PCS in comparison with the results of IT modeling approach. In general, a higher pressure jump at the compressor station means a higher compressor head, compressor rotational speed and fuel consumption rate.

It should be noted that the comparison of NIT modeling results for various ground temperatures in Table 4 also shows that there are higher values of compressor head, speed, and fuel consumption for the higher ground temperatures. This is due to the fact that at the higher ground temperatures, higher natural gas temperatures existed along the pipeline which caused greater pressure losses in the pipeline. Therefore, for the transmission of a specified natural gas mass flow rate 


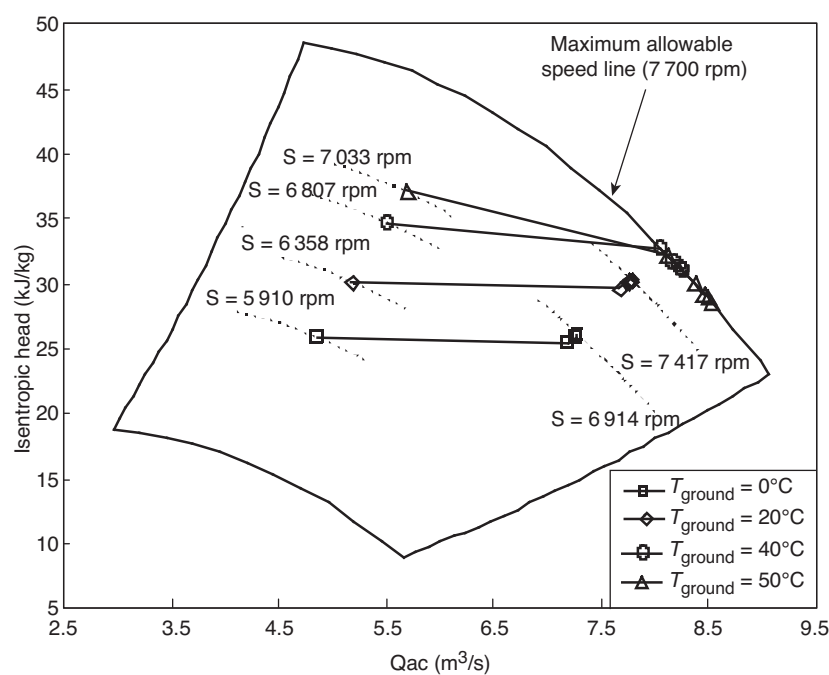

Figure 10

Time variation of compressor operating points (at the station showed in Fig. 4) obtained from NIT modeling approach for various ground temperatures from shutting down one compressor until the pipeline reached the steady state condition (about $24 \mathrm{~h}$ ).

between two specified inlet and outlet pressures, there was a greater pressure jump at the PCS (which meant higher compressor head, speed, and fuel consumption) when higher ground temperatures were studied. For example, the comparison of results in Table 4 shows that the compressor head, speed and fuel consumption were respectively $43 \%, 19 \%$, and $70 \%$ higher than that for the ground temperature of $50^{\circ} \mathrm{C}$ in comparison with the $0^{\circ} \mathrm{C}$ case study.

\subsection{N-P-D Pipeline (Unsteady Operation)}

At this section, the steady operation of the N-P-D pipeline introduced in Section 3.2 became unsteady due to a compressor shut down at the PCS. The goal was to provide the required pressure at the pipeline exit (5.86 $\mathrm{MPa}$ at Dorahan) for the specified values of the pipeline inlet pressure (7.24 MPa at Nourabad) and outlet mass flow rate (80 MMSCMD at Dorahan).

The results based on NIT modeling approach and the above mentioned boundary conditions showed two different responses for various ground temperatures $\left(0,20,40,50^{\circ} \mathrm{C}\right)$.

For the ground temperatures of 0 and $20^{\circ} \mathrm{C}$, the operating point of the two remaining compressors at the PCS moved towards the higher allowable speeds (from 5910 to $6914 \mathrm{rpm}$ for $0^{\circ} \mathrm{C}$ ground temperature case and from 6358 to $7417 \mathrm{rpm}$ for $20^{\circ} \mathrm{C}$ ground temperature case as are shown in Fig. 10) to provide the required outlet gas pressure (Fig. 11).

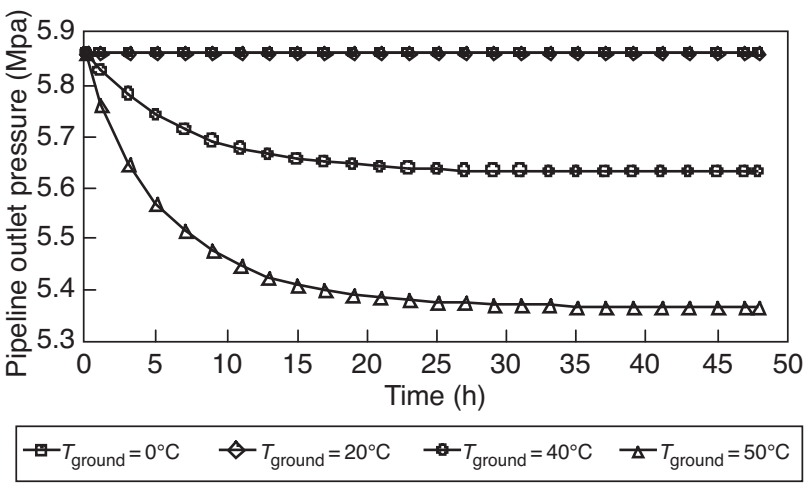

Figure 11

Time variation of pipeline outlet pressure (at Dorahan) obtained from NIT modeling approach for various ground temperatures starting from shutting down one compressor until the pipeline reached the steady state condition.

In contrast, for the ground temperatures of 40 and $50^{\circ} \mathrm{C}$, the speed of two remaining compressors had to increase higher than that of the permissible limit (7 $700 \mathrm{rpm})$ to provide the assumed required pipeline outlet pressure. For this reason for ground temperatures of 40 and $50^{\circ} \mathrm{C}$, the boundary condition of the required pressure at the pipeline exit $(5.86$ $\mathrm{MPa}$ at Dorahan) was replaced with the maximum permissible speed (7 $700 \mathrm{rpm}$ for the two remaining compressors at the PCS). Figure 10 shows that after one compressor shut down, the operating point of the two remaining compressors moved on the maximum permissible speed line for the ground temperatures of 40 and $50^{\circ} \mathrm{C}$.

As Figure 11 shows, there was the pipeline outlet pressure drop of $3.8 \%$ and $8.2 \%$ respectively for the ground temperatures of 40 and $50^{\circ} \mathrm{C}$ in 24 hours (the time at which the pipeline approximately reached the steady state operational condition).

Twenty four hours after shutting down one compressor, the steady state pipeline outlet pressure drop for the ground temperature of $50^{\circ} \mathrm{C}$ was about 2.15 times of $40^{\circ} \mathrm{C}$ ground temperature.

Therefore, the compressor station may not be able to provide the required outlet pressure at Dorahan in the above mentioned emergency situation for the higher ground temperatures.

Finally, it is worth mentioning that the results of IT modeling approach for unsteady operation of N-P-D pipeline showed $34.1 \%, 14.8 \%$ and $27 \%$ lower percent point values for compressor head, compressor rotational speed and fuel consumption rate respectively for $0^{\circ} \mathrm{C}$ ground temperature case in comparison with NIT modeling results. The above percent points changed to $16 \%, 6 \%$ and $10.1 \%$ respectively for $20^{\circ} \mathrm{C}$ ground temperature case. 


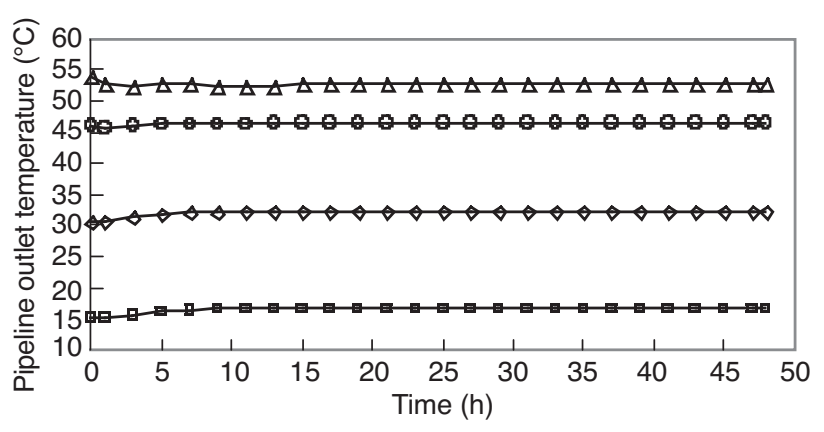

$\because-T_{\text {ground }}=0^{\circ} \mathrm{C} \quad \diamond T_{\text {ground }}=20^{\circ} \mathrm{C} \quad \rightarrow-T_{\text {ground }}=40^{\circ} \mathrm{C} \quad \triangle-T_{\text {ground }}=50^{\circ} \mathrm{C}$

Figure 12

Time variation of pipeline outlet temperature (at Dorahan) obtained from NIT modeling approach for various ground temperatures starting from shutting down one compressor until the pipeline reached the steady state condition.

Furthermore IT modeling approach showed $3.2 \%$ and 9.9\% higher percent point values for pipeline outlet pressure drop for ground temperatures of $40^{\circ} \mathrm{C}$ and $50^{\circ} \mathrm{C}$ respectively in comparison with NIT modeling results. The above mentioned results were obtained based on the final steady state numerical values of parameters which did not change noticeably after 24 hours of compressor shut down in the PCS.

Also Figure 12 shows the slight variations of pipeline outlet temperature (at Dorahan) with time during unsteady operation for various ground temperatures.

\section{CONCLUSION}

The steady state pipeline modeling results showed that the IT modeling of the gas flow caused errors in predicting the gas pressure along the pipeline. Furthermore IT modeling approach also ignored the noticeable temperature change at the compressor station. The above mentioned factors caused errors in estimating operational parameters of compressors such as compressor speed and its fuel consumption rate predicted by IT modeling approach.

The effects of ground temperature on the performance of the gas pipeline may be explained in another way too. Higher ground temperatures, increased the gas flow temperature, volumetric flow rate and pressure loss. These factors increased the required compressor power and fuel consumptions.

The unsteady operation of the N-P-D pipeline due to a compressor shut down was also studied at various ground temperatures. The results showed that, at the lower ground temperatures, the remaining running compressors could provide the pipeline outlet pressure by increasing the rotational speed in the allowable range. However at higher ground temperatures, there was need for higher compressor rotational speed than the maximum allowable limit to provide the required pipeline gas pressure. Assuming a fixed maximum allowable rotational speed for compressors also caused the lower pipeline outlet pressure than that required (with higher pressure drop at higher ground temperature).

The computing time for the NIT modeling approach was about three times of corresponding value for IT modeling approach. As an example, for the ground temperature of $0^{\circ} \mathrm{C}$, the computing time for IT and NIT modeling discussed in Section 3.2 were about 0.47 second and 1.44 second respectively on Intel (R) Core (TM) i5 $2.53 \mathrm{GHz}$. Therefore in optimizing tasks using evolutionary methods, the non-isothermal modeling may impose an excessive computing time.

\section{REFERENCES}

1 Ouyang L., Aziz K. (1996) Steady-State Gas Flow in Pipes, J.Petrol.Sci. Eng. 14, 137-158.

2 Osiadacz A.J., Chaczykowski M. (2001) Comparison of Isothermal and Non-Isothermal Pipeline Gas Flow Models, Chem. Eng. J. 81, 41-50.

3 Zhou J., Adewumi M.A. (1995) Simulation of Transient Flow in Natural Gas Pipeline, 27th Annual Meeting Pipeline Simulation Interest Group (PSIG), Aluquerque, New Mexico, October 18-20.

4 Ke S.L., Ti H.C. (2000) Transient analysis of isothermal gas flow in pipeline network, Chem. Eng. J. 76, 169-177.

5 Fauer D. (2002) The Making of A Useful Pipeline Simulation Model, 34th Annual Meeting Pipeline Simulation Interest Group (PSIG), Portland, Oregon, October 23-25.

6 Abbaspour M., Chapman K.S. (2008) Non-isothermal Transient Flow in Natural Gas Pipeline, J.Appl.Mech.75,031018.

7 Chaczykowski M. (2009) Transient flow in natural gas pipelineThe effect of pipeline thermal model, App. Math. Modell, doi:10.1016/j.apm.2009.07.017.

8 Rhoads G.A. (1983) Which Flow Equation- Does it Matter? 15th Annual Meeting Pipeline Simulation Interest Group (PSIG), Detroit, Michigan, October 27-28.

9 Schroeder D.W. (2001) A Tutorial on Pipe Flow Equations, 33rd Annual Meeting Pipeline Simulation Interest Group (PSIG), Salt Lake City, Utah, October 17-19.

10 Menon E.S. (2005) Gas Pipeline Hydraulics, CRC Press Taylor $\&$ Francis Group.

11 Stanley R.A., Bohannan W.R. (1977) Dynamic Simulation of Centrifugal Compressor Systems, Proceedings of the sixth Turbomachinery Symposium, Texas A\&M University, pp. 123-131.

12 Botros K.K., Campbell P.J., Mah D.B. (1989) Dynamic Simulation of Compressor Station Installations Including Control Systems, 21st Annual Meeting Pipeline Simulation Interest Group (PSIG), EI Paso, Texas, October 19-20.

13 Botros K.K. (1994) Transient Phenomena in Compressor Stations during Surge, J. Eng. Gas Turbines Power 116, 133-142.

14 Herran-Gonzalez A. et al. (2008) Modeling and Simulation of a Gas Distribution Pipeline Network, Appl. Math. Modell. doi:10.1016/j.apm.2008.02.012.

15 Edalat M., Ali Mansoori G. (1988) Buried Gas Transmission Pipelines: Temperature Profile Prediction through the Corresponding States Principle, Energy Sources 10, 247-252. 
16 Abdolahi F., Mesbah A., Boozarjomehry R.B., Svrcek W.Y. (2007) The Effect of Major Parameters on Simulation Results of Gas Pipelines, Int. J. Mech. Sci. 49, 989-1000.

17 Eckert E.R.G., Drake R.M. (1972) Analysis of Heat and Mass Transfer, McGraw-Hill, New York.

18 Haaland S.E. (1981) Simple and Explicit Formula for the Friction Factor in Turbulent Pipe Flow including Natural Gas Pipelines, IFAG B-131, Div Areo and Gas Dynamics, The Norwegian Institution of Technology.

19 Cengel Y.A. (2002) Thermodynamics: An Engineering Approach, McGrawHill.

20 Ehrhardt K., Steinbach M.C. (2003) Nonlinear Optimization in Gas Networks, ZIB-Report 03-46, December.

21 Bales P., Geibler B., Kolb O., Lang J., Martin A., Morsi A. (2008) Comparison of Nonlinear and Linear Optimization of Transient Gas Networks, Darmstadt university of Technology, Department of Mathematics, Preprint No. 2552.

22 Mohring J., Hoffmann J., Halfmann T., Zemitis A., Basso G. (2004) Automated Model Reduction of Complex Gas Pipeline Networks, 36th Annual Meeting Pipeline Simulation Interest Group (PSIG), Palm Springs, California, October 20-22.

23 Modisette J.L. (2000) Equation of State Tutorial, 32nd Annual Meeting, Pipeline Simulation Interest Group (PSIG), Savannah, Georgia, October 28-30.

24 Kunz O., Klimeck R., Wanger W., Jaeschke M. (2007) The GERG-2004 wide-range equation of state for natural gases and other mixtures, Verlag des Vereins Deutcher Ingenieure, Germany.

25 Hall K.R., Yaborough L. (1973) A New Equation of State for ZFactor Calculations, Oil Gas J. 82-85, 90, 92.

26 Dranchuk P.M., Purvis R.A., Robinson D.B. (1974) Computer calculations of natural gas compressibility factors using the Standing and Katz Correlation, Institute of Petroleum Technical Series IP 74-008, 1-13.

27 Dranchuk P.M., Abou-Kassem J.H. (1975) Calculation of Z Factors For Natural Gases Using Equations of State, J. Can. Petrol.Technol.14, 34-36.
28 Chaczykowski M. (2009) Sensitivity of pipeline gas flow model to the selection of the equation of state, Chem. Eng. Res. Des. 87, $12,1596-1603$.

29 Odom F.M. (1990) Tutorial on Modeling of Gas Turbine Driven Centrifugal Compressors, 22nd Annual Meeting, Pipeline Simulation Interest Group (PSIG), Baltimore, Maryland, October 18-19.

30 Percell P.B., Ryan M.J. (1987) Steady-State Optimization of Gas Pipeline Network Operation, 19th Annual Meeting Pipeline Simulation Interest Group (PSIG), Tulsa, Oklahoma, October 22-23.

31 Ransom D.L., Brun K., Kurz R. (2006) Enthalpy Determination Methods for Compressor Performance Calculations, Proceedings of PSIG The 38th Annual Meeting, PSIG 06A2, Williamsburg, VA.

32 Cohen H., Rogers G.F.C., Saravanamuttoo H.I.H. (1987) Gas Turbine Theory, Longman scientific and Technical, Wiley, 3rd edition.

33 Kurz R., Ohanian S. (2003) Modeling Turbomachinery in Pipeline Simulations, 35th Annual Meeting, Pipeline Simulation Interest Group (PSIG), Switzerland, October 15-17.

34 Santos S.P.D. (1997) Transient Analysis a Must in Gas Pipeline Design, 29th Annual Meeting, Pipeline Simulation Interest Group (PSIG), Tucson, October 15-17.

35 Walsh P.P., Fletcher P. (2004) Gas Turbine Performance, Blackwell science.

36 Kurz R., Brun K. (2009) Degradation of Gas Turbine Performance in Natural Gas Service, J. Natural Gas Sci. Eng. 1, 95-102.

37 Zhang N., Cai R. (2002) Analytical solutions and typical characteristics of part-load performance of single shaft gas turbine and its cogeneration, Energ. Convers. Manage. 43, 9-12, 1323-1337.

38 Ohanian S., Kurz R. (2003) Transient Simulation of the Effects of Compressor Outage, 35th Annual Meeting, Pipeline Simulation Interest Group (PSIG), Switzerland, October 15-17.

Final manuscript received in April 2011 Published online in May 2012 


\section{APPENDIX 1}

\section{Continuity}

$$
\begin{gathered}
\frac{\partial \rho}{\partial t}+\frac{\partial(\rho v)}{\partial x}=0 \\
\frac{\partial \rho}{\partial t}=\frac{\partial}{\partial t}\left(\frac{p}{Z R T}\right)=\left(\frac{1}{Z R T} \frac{\partial p}{\partial t}-\frac{p}{Z R T^{2}} \frac{\partial T}{\partial t} \frac{p}{Z^{2} R T} \frac{\partial z}{\partial t}\right) \underset{\frac{\partial z}{\partial t}=\frac{\partial z}{\partial p} \frac{\partial p}{\partial t} \frac{\partial z}{\partial T} \frac{\partial T}{\partial t}}{\longrightarrow} \\
\frac{\partial \rho}{\partial t}=\frac{\partial p}{\partial t}\left(\frac{1}{Z R T}-\frac{p}{Z^{2} R T} \frac{\partial z}{\partial p}\right)+\frac{\partial T}{\partial t}\left(-\frac{p}{Z R T^{2}}-\frac{p}{Z^{2} R T} \frac{\partial z}{\partial T}\right) \\
\frac{\partial(\rho v)}{\partial x}=\frac{1}{A} \frac{\partial \dot{m}}{\partial x}
\end{gathered}
$$

Substituting (a-3) and (a-2) into (a-1), gives:

$$
\frac{\partial p}{\partial t}\left(1-\frac{p}{Z} \frac{\partial z}{\partial p}\right)+\frac{\partial T}{\partial t}\left(-\frac{p}{T}-\frac{p}{Z} \frac{\partial z}{\partial T}\right)+\left(\frac{Z R T}{A}\right) \frac{\partial \dot{m}}{\partial x}=0
$$

\section{Momentum}

$$
\begin{gathered}
\frac{\partial v}{\partial t}+v \frac{\partial v}{\partial x}+\frac{1}{\rho} \frac{\partial p}{\partial x}=-f \frac{v|v|}{8 A} \pi D-g \sin \theta \\
\frac{\partial v}{\partial t}=\frac{\partial}{\partial t}\left(\frac{\dot{m}}{\rho A}\right)=\frac{1}{\rho A} \frac{\partial \dot{m}}{\partial t}-\frac{\dot{m}}{\rho^{2} A} \frac{\partial \rho}{\partial t} \\
\frac{\partial \rho}{\partial t}=\frac{\partial p}{\partial t}\left(\frac{1}{Z R T}-\frac{p}{Z^{2} R T} \frac{\partial Z}{\partial p}\right)+\frac{\partial T}{\partial t}\left(-\frac{p}{Z R T^{2}}-\frac{p}{Z^{2} R T} \frac{\partial z}{\partial T}\right) \\
\frac{\partial v}{\partial x}=\frac{\partial(\dot{m} / \rho A}{\partial x}=\frac{1}{A}\left(\frac{1}{\rho} \frac{\partial \dot{m}}{\partial x}-\frac{\dot{m}}{\rho^{2}} \frac{\partial \rho}{\partial x}\right) \\
\frac{\partial p}{\partial x}\left(\frac{1}{Z R T}-\frac{p}{Z^{2} R T} \frac{\partial z}{\partial p}\right)+\frac{\partial T}{\partial x}\left(-\frac{p}{Z R T^{2}}-\frac{p}{Z^{2} R T} \frac{\partial z}{\partial T}\right) \\
v=\frac{\dot{m}}{\rho A}=\frac{\dot{m} Z R T}{p A}
\end{gathered}
$$

Substituting (b-3) into (b-2) and (b-5) into (b-4), and then the final equations as well as (b-6) into (b-1) gives:

$$
\begin{aligned}
& \frac{\partial p}{\partial x}\left(-\frac{\dot{m} Z}{p}+\dot{m} \frac{\partial Z}{\partial p}+\frac{p A^{2}}{\dot{m} R T}\right)+\frac{\partial p}{\partial t}\left(-\frac{A}{R T}+\frac{p A}{Z R T} \frac{\partial Z}{\partial p}\right)+Z \frac{\partial \dot{m}}{\partial x}+\frac{\partial \dot{m}}{\partial t}\left(\frac{p A}{R T \dot{m}}\right)+\frac{\partial T}{\partial t}\left(\frac{p A}{R T^{2}}+\frac{p A}{Z R T} \frac{\partial Z}{\partial T}\right)+ \\
& \frac{\partial T}{\partial x}\left(\frac{\dot{m} Z}{T}+\dot{m} \frac{\partial Z}{\partial T}\right)+f \frac{|\dot{m}|}{8 A} \pi D Z+g \sin \theta \frac{p^{2} A^{2}}{\dot{m} Z(R T)^{2}}=0
\end{aligned}
$$




\section{Energy}

$$
\begin{gathered}
\rho \frac{d h}{d t}-\frac{d p}{d t}=\frac{\Omega}{A}+f \frac{\rho v^{2}|v|}{8 A} \pi D \\
\frac{d h}{d t}=c p \frac{d T}{d t}+\left(1+\frac{T}{\rho}\left(\frac{\partial \rho}{\partial T}\right)_{p}\right) \frac{1}{\rho} \frac{d p}{d t} \\
\left(\frac{\partial \rho}{\partial T}\right)_{p}=\frac{p}{R}\left(-\frac{1}{Z T^{2}}-\frac{1}{T Z^{2}} \frac{\partial Z}{\partial T}\right)
\end{gathered}
$$

Substituting (C-3) into (C-2) and the result into (C-1) gives:

$$
\begin{aligned}
& \rho c p\left(\frac{\partial T}{\partial t}+v \frac{\partial T}{\partial x}\right)+\left(-\frac{T}{\rho} \frac{p}{R}\left(\frac{1}{Z T^{2}}+\frac{1}{T Z^{2}} \frac{\partial Z}{\partial T}\right)\right)\left(\frac{\partial p}{\partial t}+v \frac{\partial p}{\partial x}\right)=\frac{\Omega}{A}+f \frac{\rho v^{2}|v|}{8 A} \pi D \Rightarrow \\
& c p \frac{\partial T}{\partial x}+\frac{\partial T}{\partial t}\left(\frac{A}{\dot{m}} \frac{p c p}{Z R T}\right)+\frac{\partial p}{\partial x}\left(-\frac{R T Z}{p}-\frac{R T^{2}}{p} \frac{\partial Z}{\partial T}\right)+\frac{\partial p}{\partial t}\left(-\frac{A}{\dot{m}}-\frac{T}{Z} \frac{A}{\dot{m}} \frac{\partial Z}{\partial T}\right)-\frac{\Omega}{\dot{m}}-f \frac{\dot{m}|\dot{m}|}{8 A^{3}} \pi D\left(\frac{R T Z}{p}\right)^{2}=0
\end{aligned}
$$

